\title{
LATENT HETEROGENEITY IN WTP ESTIMATES OF NON-MONETARY SOCIAL COSTS OF MOTOR VEHICLE USE FROM MULTI-ATTRIBUTE STATED CHOICES*
}

\author{
by Michelle PARUMOG**, Shoshi MIZOKAMI***, and Ryuji KAKIMOTO****
}

\section{Introduction}

Increasing concerns for the impact of transport on the environment has prompted many researchers and policymakers to search for the ultimate solution to achieve sustainable mobility. The solution is often not generic and varies according to country contexts. Many of the difference are due to mobility choices that reflect local priorities ${ }^{1}$. In policy appraisal, one of the major challenge are the valuation of the different components of the total social cost of traffic particularly that of motorized vehicles. The functions of these social costs estimates are mainly to evaluate full-cost of transport programs and projects, for efficient pricing to ensure efficient use and to prioritize efforts to reduce costs and improve benefits ${ }^{2}$. Many studies, particularly in the United States and Europe, have been done in attempt to fully account the value the social cost of motorization ${ }^{3)-5 \text { ) }}$. These studies have considerable deviations in the categorization and scope of value components. In early studies, values are classified into internal costs (also called direct, personal costs) and external costs ${ }^{6}$. Others consider further classification of these two major costs into either monetary or non-monetary costs ${ }^{7}$, or user and non-user costs components ${ }^{8}$. Methodologically, non-monetary items are harder to value than monetary items and require techniques such as hedonic pricing or stated-preference valuation methods. In this study, we aim to value some non-monetary components of social costs of motor vehicle use such as the external costs borne by users, air pollution and noise costs, and the direct non-monetary costs, risk value of traffic fatalities. An empirical application was done here using internet stated route choice experiment conducted among private work trips in Metro Manila.

The survey involves eliciting drivers' preferences for route considering hypothetical improvements in road and roadside environmental attributes. Preferences for changes in environmental systems are difficult to understand. Difference in perceptions of environment characteristics, attitudes and social norms, and beliefs and knowledge usually causes variations in environmental preferences ${ }^{9)}$. In pricing social costs of using motorized vehicles, modeling heterogeneity of preferences is important in three ways: (1) identifying latent WTP segments for accurate estimation of values; (2) understanding environmental preferences for strategic policy-making; and (3) developing models that are more precise for benefit transfer. There are various ways of specifying preference heterogeneity in a multi-attribute discrete choice problem. In discrete choice analysis, heterogeneity may be addressed by considering functional form of the indirect utility, accounting for differences in tastes parameter in the utility function, incorporating heterogeneity in decision rule, inconsistent choice sets, and disturbance structure in structural equations ${ }^{10}$. In valuation problems, models that that accounts for heterogeneity in taste parameter are the models that best explain variance in WTP. A very important consideration prior to this modeling heterogeneity is the factors affecting difference in taste. Difference in tastes is caused by observed or unobserved variables, or the combination of both. If the cause of heterogeneity is mainly due to exogenous variables, interaction of main effects and variables explaining tastes variance are introduced to the structural equations resulting in nonlinear form. Preferences can likewise be assumed to be cause by latent factors. There has been an increasing interest in considering unobserved heterogeneity in recent environmental valuation studies ${ }^{11)}{ }^{12}$. One of the reasons is that ecological behavior is established to be influenced by latent characteristics of individuals such as environmental attitudes and perceptions ${ }^{13)}$.

This paper aims to address latent preference heterogeneity by assuming random taste parameter in a multi-attribute stated choice valuation problem. We investigate two ways in specifying the distribution of the parameters, using discrete distributions in latent class model and mixture distributions in mixed logit. We aim to discuss methodological usability of the models on the context of WTP estimates from an empirical

\footnotetext{
*Keywords: WTP, environmental valuation, latent heterogeneity

**Member of JSCE, Dr. Eng., Institute for Transport Policy Studies,

(3-18-19 Toranomon, Minato-ku, Tokyo, Japan, TEL: 81-3-5470-8415, FAX: 81-3-5470-8419)

***Member of JSCE, Dr. Eng., Dept. of Env'1 and Civil Eng., Kumamoto University,

(2-39-1, Kurokami, Kumamoto City, Japan, TEL 81-96-342-3541, FAX81-96-342-3507)

****Member of JSCE, Ph.D., Dept. of Env'l and Civil Eng., Kumamoto University,

(2-39-1, Kurokami, Kumamoto City, Japan, TEL 81-96-342-3541, FAX81-96-342-3507)
} 
application on the valuation of social costs components of motor vehicle use in Metro Manila from stated choice experiment.

\section{Empirical Application}

(1) Study context

The urban primacy of Metro Manila is characterized by high motorization in the region. Above 40 percent of all registered vehicles in the Philippines is in Metro Manila and are producing about 17.5 million trips a day ${ }^{14)}$. The trend is still increasing and implying greater environmental impact to the network. Ambient air and noise standards, for instance, are exceeded in many areas. In the 2001 preliminary assessment of outdoor air pollution and health in Metro Manila conducted by University of the Philippines, the average annual total suspended particulate (TSP) is $153 \mu \mathrm{g} / \mathrm{m} 3$ which is about 70 percent more than the national standard which is $90 \mu \mathrm{g} / \mathrm{m} 3$. Concentrations of particulate matter with a diameter not less than 10 microns $\left(\mathrm{PM}_{10}\right)$ are found to go above standards in major traffic arteries. Moreover, the noise standard of 80 decibels is exceeded even in some residential areas. Few studies, mainly valuing direct cost components of the social costs of motorized transport, have been done in Metro Manila. Roth and Viloria ${ }^{15)}$ measured social cost of congestion and proposed a congestion charge in the range of 6 to 14 Philippine peso (PhP) per passenger car unit per $\mathrm{km}$ to increase travel speed by 44 to 101 percent. Premature deaths from $\mathrm{PM}_{10}$ were estimated to range from 0.5 to 14.3 billion $\mathrm{PhP}$ in $1992^{16)}$. Fabian and Vergel ${ }^{17)}$ estimated an average 1.24 PhP WTP to equip diesel exhaust of jeepneys with particulate trap. In 2003, Asian Development Bank (ADB) sponsored a research on market-based instruments to evaluate air pollution control policy options ${ }^{18)}$. The social cost of fatal accident, on the other hand, was estimated by de Leon et al. ${ }^{19)}$ to be $506,450 \mathrm{PhP}$. Most of the existing studies use market based instrument to put values to some components of the social cost of motorization. In this study, we present a valuation framework of multi-dimension non-monetary social cost of motor-vehicle use using stated valuation model.

(2) Stated choice model and non-market valuation

Preference data are important in predicting behavior that is an important input in wide array of policies and decision-making exercises. Lack of markets for public goods leave researchers to rely on stated choices based on hypothetical scenario and alternatives for preference data. Stated choice models (SCM) are used to analyze these data as they are founded on sound microeconomic theory. Attribute-based SCM is an approach where the respondents are asked to make a choice among alternatives with a range of attributes ${ }^{20)}$. In contrast, contingent valuation method (CVM) entails willingness to pay (WTP) value elicitation in an open or closed form on the context of make-believe circumstances that present improvement or damage to existing environmental conditions. If price is the only attribute considered in multi-attribute SCM, the methods are similar. In some way, this makes multi-attribute stated choice model a variant of CVM. Environmental valuation studies using choice models are limited compared to CVM and other environmental valuation methods such as hedonic pricing and travel cost. However, some researchers indicate preference for choice models due to some advantages. Firstly, its ability to deduce behavioral tendencies of respondents over variation of goods' dimension such as attribute or component levels significantly trim down the need for costly survey needed in CVM. Secondly, policy implications in choice modeling are less suggestive and, thus, less susceptible to context biases or behavioral heuristics ${ }^{21}$. Moreover, it avoids some instrumental biases such as zero protest votes present in CVM ${ }^{22}$.

In terms of policy implications, results from multi-attribute stated choice models present more room for policy interpretation. The good in question, for instance, can be varied according to quality and quantity level depending on experimental design. In most evaluation cases, measures such as sustainability targets and financial resources sets project phasing. Flexibility of choice models allows value estimates for incremental changes in good. Also, the model itself allows for better prediction of consumer behavior and interpretation of preference diversity.

\section{(3) Experimental design}

We experimented on a route choice problem where, apart from the current route taken, two alternative routes with varying environmental improvements in air and noise quality, greenery and streetscape, road safety. Attributes were assigned to vary randomly. This stated choice problem is repeated six times. In this study, we use only the four of these repetitions with equal attribute dimensions.

Deterministic route choice model relies heavily on travel time and travel cost as factor of preference. This 
framework is constantly improved as subjective attributes such as environmental quality, time reliability, and road safety are found to be some of the attributes equally significant. In this study, we focused on subjective variables corresponding to environmental attributes of the road and roadside we wanted to investigate (i.e. air pollution, noise, accident risk).

As air quality is a complex concept to grasp when done in pollutant-specific manner, we present it in percentages of improvement. This can readily translate into unit reductions or scaling of regional air quality index which is an aggregate scale describing concentrations of major pollutants such as carbon monoxide (CO), sulphur dioxide $\left(\mathrm{SO}_{2}\right)$, nitrogen dioxide $\left(\mathrm{NO}_{2}\right)$, ozone $\left(\mathrm{O}_{3}\right)$ and fine particular matter in policy context. Noise is likewise offered in percentages of reduction. Greenery and streetscape are with or without scenario. However, in this paper, analysis excludes greenery and landscape as they have insignificant effect in early model runs. A possible explanation is that due to limited information-processing, the respondent apply simplifying strategies that eliminates this variable from utility evaluation ${ }^{23}{ }^{24)}$. Road safety was presented by giving figures of annual road fatalities. In the current route, the number of fatalities a year is pegged at 150 . A screen shot of the hypothetical situation, where inputted travel time and costs are 20 minutes and 30 pesos respectively, is presented in Figure 1. This screen, with different attribute dimensions, was repeated six times in the questionnaires.

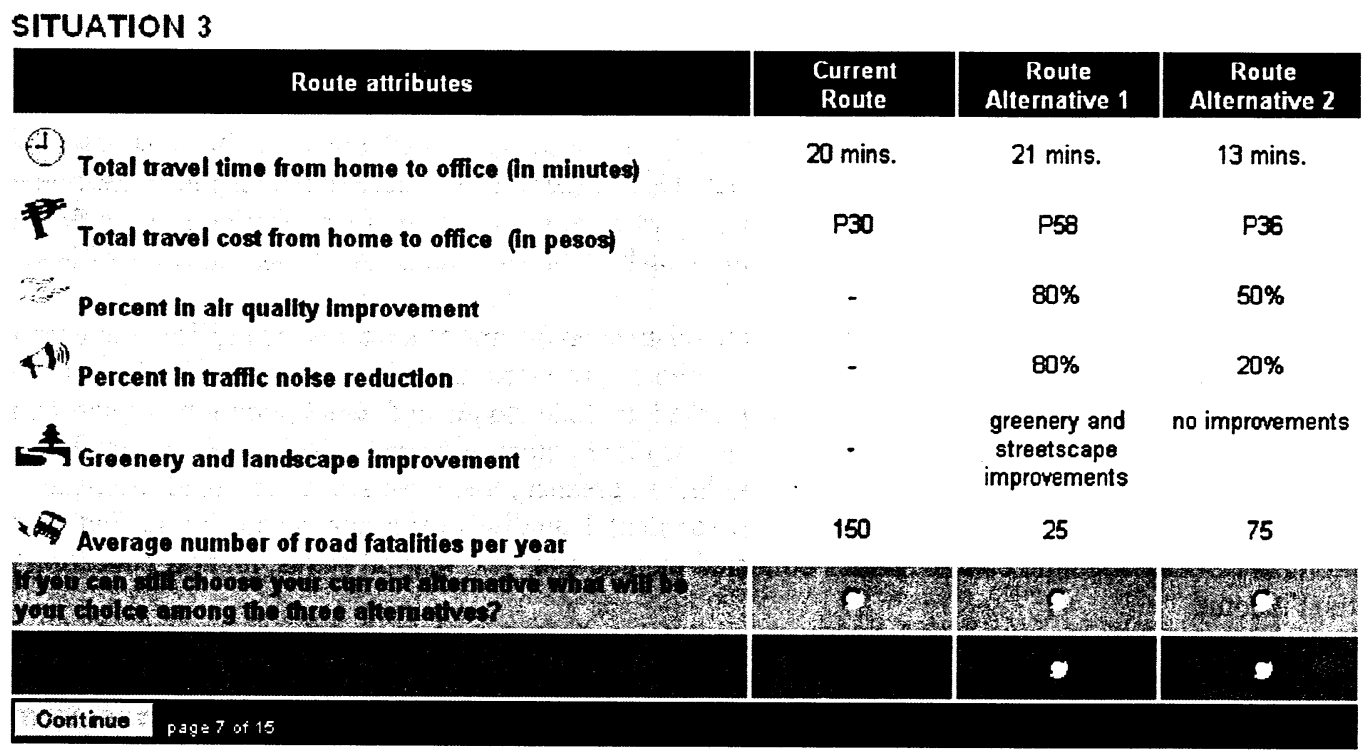

Figure 1: Sample screen of the SP route choice

Table 1 shows how the attributes are determined for the hypothetical route alternatives. Random noise is added to actual inputted travel time TT and actual travel cost TC. The noise is deemed as a random draw from normal distribution with standard deviation that is one-third the value of TT. On the other hand, noise for TC entails addition of the absolute value of a random draw from normal distribution with standard deviation that is one-third the value of TC. In the other attributes, embedded scripts performed random drawing of the attributes levels.

Table 1: Attributes levels

\begin{tabular}{|c|c|c|}
\hline Attributes & Current & Attribute levels \\
\hline Travel time: & $T T$ & $T T+\mathrm{R} \sim \mathrm{N}(0, \mathrm{TT} / 3)$ \\
\hline Travel cost: & $T C$ & $T C+|\mathrm{R} \sim \mathrm{N}(0, \mathrm{TC} / 3)|$ \\
\hline Air Quality Improvement: & Base & $20 \%$ improvement, $30 \%$ improvement, $80 \%$ improvement \\
\hline $\begin{array}{l}\text { Reduction in Noise } \\
\text { Pollution: }\end{array}$ & Base & $20 \%$ reduction, $30 \%$ reduction, $80 \%$ reduction \\
\hline Greenery and streetscape: & Base & $\begin{array}{l}\text { greenery and streetscape } \begin{array}{c}\text { improvements, } \\
\text { improvement, } \\
\text { improvements }\end{array} \\
\text { streetscape improvement, and no }\end{array}$ \\
\hline Road fatalities/year: & 150 & $20,50,75$ and 100 \\
\hline
\end{tabular}




\section{Data collection}

Major cities in Asia now have improved access to internet because of decreasing cost of computers and infrastructure improvement brought about by market competitions. A recent survey shows that in 2004, there are about 11.8 million internet users in the Philippines. This represents about 16 percent internet rate. This figure is projected to increase to 20 million by 2007 . Moreover, $70-80$ percent of internet transactions are business to business. The disadvantages in internet survey such as low response rate and presence of unreasonable responses are redeemed by some of its inherent advantages that include fast response rate, less interviewer effects, and more intelligent questionnaire. Internet survey can be designed to be more realistic as web pages can be embedded with script that increase interactivity such as recalling prior inputs, performing mathematical calculations, and calling random variables. Unique identification numbers can identify respondents for easy response verification. Conversely, consideration in questionnaire length, keeping respondents' interest, and presentation are some of necessary consideration.

Web survey of private work trips in Metro Manila was conducted for about three weeks, from June 5 to July 1,2005 . Samples were drawn by emailing human resource department heads of different private offices, government offices, non-government offices, and institutions listed in various online directories. They were informed of the purpose and timeframe of the study and were asked to forward the website to the personnel of their offices. One follow-up e-mail was done for each mail-out. We received a total of 83 filled questionnaires which were reduced to 80 after invalid responses were removed. Three SP choice data with same attribute dimension were gathered for this study. Lexicographic and unreasonable responses were further eliminated to translate into 221 useful SP data. This suggests that unacceptable response rate amounts to 31 percent of total. Since it is very hard to estimate participation rate as it is very difficult to verify which e-mail was actually opened, response - mail-out rate which yield 16 percent can be an indicator of how the survey was accepted.

The questionnaire has five parts: work trip characteristics; environmental quality perception in commonly used route; environmental attitudes; the experimental choice problems; and the socioeconomic characteristics of respondents. Characteristics of the work trip asked include home and work location, motor-vehicle characteristics, travel time and cost to work. A 5-level scale of commonly used route's environmental quality perception, which consists of air pollution, noise pollution, greenery and streetscape, and road safety, as well as a 10-level perception scale of the general environmental quality rating composed the second part of questionnaire Socioeconomic characteristics collected include age, sex, marital status, highest education and personal income.

Table 2 summarizes the characteristics of the sample. Average travel time and travel cost are about 43 minutes and 102 pesos respectively. About 74 percent of the respondents are male and 75 percent are private worker. Most of the respondents had completed 14 years of formal education and 37 percent are not married. Average income of the sample is about 65 thousand $\mathrm{PhP}$ a month. As the sample represents car users that have relatively high income, internet access did not seem to bias the sample. It is however noteworthy that sample income is biased towards the upper half of income distribution of Metro Manila. Moreover, 85 percent belongs to the upper ten percent of the income distribution.

Table 2: Descriptive characteristics of sample

\begin{tabular}{lrrrr}
\hline Explanatory Variable & \multicolumn{1}{c}{ Mean } & Minimum & Maximum & Std. Dev. \\
\hline Travel time (minutes) & 42.56 & 3.00 & 120.00 & 26.48 \\
Travel cost (PhP) & 102.00 & 9.00 & 300.00 & 75.33 \\
Age & 36.83 & 21.00 & 64.00 & 9.98 \\
Sex (1 male, 0 female) & 0.74 & 0.00 & 1.00 & 0.44 \\
Status (1 married / been married, 0 single) & 0.63 & 0.00 & 1.00 & 0.49 \\
Employment type (1 private, 0 others) & 0.75 & 0.00 & 1.00 & 0.44 \\
Years of education & 14.35 & 10.00 & 16.00 & 0.99 \\
Income ('000 PhP) & 65.43 & 7.50 & 200.00 & 53.48 \\
\hline
\end{tabular}




\section{Specification of utility and welfare measure}

(1) Multi-attribute utility

Route choice utility depends on the route characteristics or attributes, a function of the socioeconomic characteristics of the respondents and the stochastic or random part of utility. Route attributes can be classified into the objective attributes, travel time and travel cost, and subjective attributes such as like environmental quality, safety, and view. We define the indirect utility associated with alternative $j$ and individual $i$ as:

$$
U_{j i}=\sum_{M} \beta_{M} x_{M j i}+\beta_{p} x_{p j i}+\sum_{E V} \beta_{E V i} x_{E V j i}+\varepsilon_{j i}
$$

where $x_{p i i}$ is the cost vector, $x_{M j i}$ stands for the matrix of other attributes, $x_{E V j i}$ are the socioeconomic explanatory variables, $\beta$ are the associated taste parameter, and $\varepsilon_{j i}$ is the random unmeasured utility components. The indices $p, M$, and $E V$ stands for price, attributes and explanatory variables, respectively. In this utility specification, attributes are assume to be independent of each other, meaning preference over one attribute do not affect other attributes preference, and, thus, follow additive relationship. To determine robustness of models incorporating taste heterogeneity, we estimated logit model with linear indirect utility function for each $j$ alternative specified linearly as:

$$
V_{j i}=\alpha_{j}+\beta_{t} x_{t i j}+\beta_{a} x_{a j i}+\beta_{n} x_{n j i}+\beta_{f} x_{f j i}+\beta_{p} x_{p j i} .
$$

This utility specification considers the main variables (with indices in parentheses) cost $(p)$ and main effects attribute variables consisting of time $(t)$, air quality $(a)$, noise $(n)$, and traffic fatality $(f)$. The parameter $\alpha$ stands for the alternative specific constant.

(2) Welfare measures

Assuming effects of attributes are captured in deterministic part, WTP indicator in this choice problem can be described as the marginal substitution rate of the perceived attributes, say air quality, $x_{a j i}$ and the cost $x_{p j i}$ at constant utility for each observation $i$. In a simple fixed linear specification of utility, the subjective value of the improvement of air quality ( $\left.S V_{a}\right)$ can be computed as the ratio of air quality coefficient $\beta_{a}$ and cost coefficient $\beta_{p}$. The same follows in the computation of subjective values of time, noise, and fatal accidents (i.e. $S V_{t} S V_{n}$, and $S V_{f}$ ).

$$
S V_{a}=-\left.\frac{d x_{p j i}}{d x_{a j i}}\right|_{V}=\frac{\partial V / \partial x_{a j i}}{\partial V / \partial x_{p j i}}=\frac{\beta_{a}}{\beta_{p}}
$$

The computation of the welfare estimate becomes more complicated in random coefficient model. As attribute and/or price coefficient are distributed. This indicates a distributed WTP estimate. The ratio of two normally distributed random variables, for instance, follows a Cauchy distribution without moments. The interpretation of this distribution can be made simpler by adopting a fixed cost coefficient that will simply yield a normally distributed random variable. Another issue is the pretext of positive coefficients that is inevitable in distribution such as normal distribution. Various distributions such as lognormal triangular, and bounded normal has been used to address this issue. However, positive coefficient may be not at all counter intuitive to rational economic behavior. Hess ${ }^{25}$ mentioned the affect of conjoint activities in the case of desirable travel experience as one of the possible reasons of preferences not following rational tendencies. This can be applied in the case of valuing route attributes where attributes such as air quality, noise, and traffic fatalities are indicators of risk or comforts may change preferences for other more deterministic elements of the choice attributes.

\section{Latent class model}

Latent class model (LCM) is one way of modeling heterogeneity using random parameters where, unlike mixed logit where parameters have continuous distribution, parameters have discrete distribution. The applications of these models have lately found its way in environmental valuation. Milon ${ }^{12)}$, for instance, use 
latent class choice model to determine whether socioeconomic factors and environmental attitudes causes variations in respondents' preferences and attitudes for restoration of the Greater Everglades wetland ecosystem. Various studies have also been conducted comparing latent class method and random coefficient method. Provencher ${ }^{26)}$, for instance, compared these two ways of accounting heterogeneity in salmon fishing in Lake Michigan and found that the two methods have merits in their own way. A number of models used to evaluate transport system have likewise been done ${ }^{10)} 27$.

One of the advantages of LCM over mixed logit is that it is easily estimable using the reliable MNL procedures. Early empirical works on the use of latent class in choice modeling were done by Swait ${ }^{28)}$ and Bhat ${ }^{29)}$. Bhat refers to this model as endogenous segmentation model. LCM assumes that individual behavior depends on observable attributes and on latent heterogeneity that varies according to what the researcher assumes to be unobservable. Here, it is assumed that individuals are implicitly classified into a set of unknown or unobserved $q$ classes, $q=1 \ldots Q$. The core of the analysis is then a logit behavioral model that involves individual $i$ choosing alternative $j$ from choice set $C_{j}$ conditioned on class $q$ may be written as:

$$
P_{j i \mid q}=\frac{\exp \left(V_{j i}\right)}{\sum_{j=1}^{J} \exp \left(V_{j i}\right)} .
$$

However, since the each class segment $q$ is assumed to have differences in taste, the parameter vector $\beta$ in $V_{j i}$ is conditioned on class $q$ and thus can be denoted as $\beta_{q}^{\prime}$ to denote parameter vector for each class $q$. On the other hand, let $S_{i q}$ denote the membership probability of individual $i$ in latent or unobserved class $q$. The class probability follows any convenient discrete probabilistic distribution such as the logit below.

$$
S_{i q}=\frac{\exp \left(\gamma_{q} z_{i}\right)}{\sum_{q=1}^{Q} \exp \left(\gamma_{q} z_{i}\right)}, q=1 \ldots Q, \gamma_{Q}=0
$$

The notation $z_{i}$ represents vectors of variables which enter the model to describe class membership and its parameters $\gamma$. The parameter $\gamma_{Q}$ is normalized to zero to secure identification of the model ${ }^{30)}$. The latent class probabilities should sum to one by specifications.

The unconditional probability that an individual $i$ chooses alternative $j$ can thus be formulated using probabilities taken as particular class contribution as below.

$$
P_{j i}=\sum_{q=1}^{Q} S_{i q} P_{i j \mid q} .
$$

The log likelihood for the sample is

$$
L o g L=\sum_{i=1}^{N} \log P_{i}=\sum_{i=1}^{N} \log \left[\sum_{q=1}^{Q} S_{i q}\left(\prod_{j=1}^{J} P_{j i \mid q}^{\delta^{j i q}}\right)\right]
$$

where $\delta^{j i q}$ takes a value 1 if $i$ chooses $\mathrm{j}$ alternative given class $\mathrm{q}$, and 0 otherwise. Maximization of the $\log$ likelihood with respect to the $Q$ structural parameter vectors, $\alpha$ and $\beta$ and the $Q-1$ latent class parameter vectors $\gamma_{q}$ is a conventional problem in maximum likelihood estimation. However, the maximization of this problem has been documented to have unstable condition using Newton or quasi-Ncwton routine. Bhat ${ }^{29)}$ recommends maximum likelihood iteration with good start parameter estimate using two-stage iterative method using Expectation- Maximization (EM) group of algorithm ${ }^{31)}$. 


\section{Mixed multinomial logit}

Environmental amenities, just like any subjective attribute in a stated choice question, are complex concepts that vary according to individual. For example, in a work trip route choice problem, a person with a flexible work schedule may seek a route with better environmental quality than a person which is already running late for work. The difference in how an individual realize degree of alternative's attributes weight like congestion or presence of pollution causes parameters of discrete choice structural equations to follow certain distribution. Since tastes and perception varies per individual, it is not likely for the estimated coefficients to be fixed or common across observations. To consider this, we estimate a mixed logit model where not only stochastic part of the indirect utility, but also alternative attribute coefficients, varies randomly. We follow Train ${ }^{33)}$, and assume that $\beta$ follows a continuous normal distribution the choice probability is defined as:

$$
P=\int\left(e^{V_{j}} / \sum_{j} e^{V_{j}}\right) \phi(\beta \mid b, \Omega) d \beta
$$

where $\phi(\beta \mid b, \Omega)$ is a normal density with mean $\mathrm{b}$ and covariance $\Omega$. This can be estimated by maximum simulated likelihood where $P$ is estimated by drawing values of $\beta$ from assumed density, then calculating average to compute the simulated probability $\bar{P}_{n j}$ as follows:

$$
S S L=\sum_{n=1}^{N} \sum_{j=1}^{J} \theta_{n j} \ln \bar{P}_{n j}
$$

where $\theta_{\mathrm{ni}}$ is the choice dummy. Mixed logit allows for flexible specification as it permits heterogeneity, correlation and taste variations in data. Complex representation of attributes of the environmental goods presents a challenge in the structural equations of models. For example, valuation of water quality where attributes are disaggregated into toxicity and transparency of waters may cause inherent correlation between the two attributes, as some individual may perceive good water transparency to equate with low toxicity. This can be represented by correlated random coefficient which can be denoted as follows.

$$
\beta_{M} \sim M V N\left(\bar{\beta}_{M}, \Omega\right)
$$

This involves an attributes parameter vector $\beta_{M}$ that has multivariate normal distribution with estimator $\bar{\beta}_{M}$ and variance-covariance matrix $\Omega$. The covariance structure of parameter reflects the correlation pattern of the parameter estimates. Various useful inferences can be derived from the covariance and correlation pattern of the attributes' parameter. One is the relationship of attribute scales, useful in explaining attribute trade-off. Another is the relative complexity of the choice process. Negative correlation coefficient usually shows this complexity.

\section{Estimation and findings}

(1) Model estimation

Table 3 shows the parameter estimates of the different models and t-statistics shown in the parentheses of the multinomial logit (MNL), the latent class models (LCM and various specifications of the mixed multinomial logit (MMNL). In MMNLFC, the coefficient of cost is held fix while in MMNLCOV, attribute parameters are assumed to follow a multivariate distribution. In the LCM, we selected the two segments model as the best model from some estimations based on BIC. MNL and LCM model was estimated using TSP while the MMNL models were estimated using a non-commercial estimation package BIOGEME ${ }^{34)}$. Three types of mixed logit models were estimated. In MMNLFC, the cost parameter was held fix as the estimate in MMNL show insignificant variation in cost parameter. The MMNLCOV model, on the other hand, shows the estimates of parameters with distributions that follow multivariate normal distribution as described in eq. 11. In the LCM model only 193 data, with latent class segmentation variables, are used. 
Table 3: Parameter estimates of models

\begin{tabular}{|c|c|c|c|c|c|c|}
\hline & \multirow{2}{*}{ MNL } & \multicolumn{2}{|c|}{ LCM } & \multirow{2}{*}{ MMNL } & \multirow{2}{*}{ MMNLFC } & \multirow{2}{*}{ MMNLCOV } \\
\hline & & segment 1 & segment 2 & & & \\
\hline$\overline{\alpha_{2}{ }^{1}}$ & $2.20(-4.49)$ & $10.19(-0.80)$ & $-0.67(-0.47)$ & $3.29(-1.56)$ & $45.91(-1.17)$ & \\
\hline$\alpha_{3}{ }^{1}$ & $2.02(-4.04)$ & $10.37(-0.81)$ & $-3.92(-1.33)$ & $3.13(-1.48)$ & $45.38(-1.15)$ & $96.8(-36.47)$ \\
\hline$\beta_{p}($ Travel cost $)$ & $-0.01(-3.60)$ & $-0.01(-2.31)$ & $-0.01(-0.69)$ & $-0.02(-1.42)$ & $-0.32(-1.08)$ & $-0.87(-13.95)$ \\
\hline$\sigma_{p}$ & & & & $0.00(-0.32)$ & & $1.29(-10.63)$ \\
\hline$\beta_{t}$ (Travel time) & $-0.04(-4.79)$ & $-0.02(-1.57)$ & $-0.18(-1.47)$ & $-0.08(-1.90)$ & $-1.4(-1.13)$ & $-2.93(-10.65)$ \\
\hline$\sigma_{t}$ & & & & $0.08(-1.24)$ & $1.42(-1.12)$ & $5.12(-11.78)$ \\
\hline$\beta_{a}$ (Air quality) & $-0.50(-1.21)$ & $-0.58(-0.83)$ & $-0.30(-0.17)$ & $-0.99(-1.05)$ & $-15.5(-1.01)$ & $-15.34(-2.57)$ \\
\hline$\sigma_{a}$ & & & & $-1.13(-0.17)$ & $45.21(-1.16)$ & $42.38(-7.82)$ \\
\hline$\beta_{n}$ (Noise) & $-0.55(-1.42)$ & $-0.30(-0.53)$ & $0.22(-0.12)$ & $-0.93(-1.04)$ & $-18.16(-0.93)$ & $-21.68(-3.23)$ \\
\hline$\sigma_{n}$ & & & & $-2.59(-1.13)$ & $50(-1.16)$ & $-36.38(-6.86)$ \\
\hline$\beta_{f}$ (Fatal accidents) & $-0.01(-4.21)$ & $-0.01(-3.00)$ & $0.00(-0.38)$ & $-0.02(-2.09)$ & $-0.28(-1.03)$ & $-0.66(-9.15)$ \\
\hline & & & & $-0.02(-0.97)$ & $0.38(-1.12)$ & $0.21(-6.29)$ \\
\hline$\gamma_{1}$ (Air quality perception) & & 0.25 & 1.12) & & & \\
\hline$\gamma_{2}$ (Safety perception) & & 0.41 & 2.14) & & & \\
\hline Latent class prob. & & 0.52 & 0.48 & & & \\
\hline Parameters & 7 & & 16 & 12 & 11 & 22 \\
\hline $\mathrm{N}$ & 221 & & 193 & 221 & 221 & 221 \\
\hline LR & 80 & & 135 & 87 & 93 & 83 \\
\hline Adjusted & 0.136 & & 0.174 & 0.129 & 0.146 & 0.080 \\
\hline
\end{tabular}

1 alternative specific constant

${ }_{2}^{2}$ parameter covariance matrix is shown in Table 4

(2) Latent heterogeneity in parameter estimates

Models considering latent heterogeneity by means of distributed taste parameters are more robust than the fixed parameter MNL model. MMNL model shows that cost parameter did not significantly vary across sample. A marginal improvement in the model was gained when the cost parameter was held fix in MMNLFC. More so, in MMNLCOV, the taste variations seem to be correlated in some attributes. The following Table 4 shows covariance and correlation of the attribute distribution.

Table 4: Covariance and correlation $(\beta)$ of attribute parameters

\begin{tabular}{|c|c|c|c|c|c|c|c|c|}
\hline & \multirow{2}{*}{$\begin{array}{r}\beta_{p} \\
\text { Est.(t-stat) }\end{array}$} & \multirow[b]{2}{*}{$\rho$} & \multicolumn{2}{|c|}{$\beta_{t}$ (Travel time) } & \multicolumn{2}{|c|}{$\beta_{a}$ (Air quality) } & \multicolumn{2}{|c|}{$\beta_{n}$ (Noise) } \\
\hline & & & Est.(t-stat) & $\rho$ & Est.(t-stat) & $\rho$ & Est.(t-stat) & $\rho$ \\
\hline$\beta_{t}$ (Travel time) & $0.52(9.05)$ & 0.08 & & & & & & \\
\hline$\beta_{a}$ (Air quality) & $-35.42(5.17)$ & -0.65 & $-53.56(8.69)$ & -0.98 & & & & \\
\hline$\beta_{n}$ (Noise) & $-36.72(4.75)$ & 0.78 & $8.06(1.46)$ & -0.04 & $-36.72(4.75)$ & 0.02 & & \\
\hline$\beta_{f}$ (Fatal accidents) & $-0.09(2.35)$ & -0.32 & $0.60(11.10)$ & 0.55 & $-0.60(10.32)$ & -0.07 & $0.07(2.47)$ & -0.01 \\
\hline
\end{tabular}

In the LCM and all the mixed logit models, the significance of the air and noise parameters is relatively marginal compared to parameters associated to variables such as cost, time, and fatal accidents. Moreover, heterogeneity in taste as indicated by the scale of standard deviation estimates of parameter distributions is more extensive for air and noise. This means that in choosing alternative routes, respondents may not have determined preferences for subjective attributes that do not directly affect their trip. As seen in the covariance of the attribute parameter distribution, the tendency of the respondent is to associate these subjective attributes to those attributes which entail personal monetary costs. The negative correlation of travel time parameter over the parameter of air and noise pollution shows the tendency of the respondents to value time lower as the environmental quality of the two attributes improves. This relationship is more pronounce between time and air where the correlation coefficient is about -0.98 . These indicate that preference heterogeneity may be more pronounced for traffic externalities than risks or opportunity cost.

(3) Perceptions and heterogeneity

The explanatory variables in class segmentation in LCM provide insights on the latent factors that affect heterogeneity. Various variables were tested but only the ordinal variables on perceptions on air quality and safety of the current route taken shows considerable significance. In addition to common results in valuation studies that environmental attitudes are the common cause of heterogeneity in WTP estimates, here, we present that perception of environment are likewise influential. The latent class derived in the estimation split the sample into 52 and 48 percent segments. The first segment are the ones with lower value for time and 
higher value for the environmental attributes and the other segments consist of those with higher value for time and lower value for the environmental attributes. The first segment may be related to the segment of the population that perceived badly the environment while the other may be related to those who think that there is no significant environmental problem.

(4) Welfare Estimates

Estimates of WTP for the different road and roadside environment attributes are shown in Table 5. Except for the WTP for noise reduction, point estimates of the mixed logit models lies between estimates of the latent class model segments estimate.

Table 5: WTP Estimates for Non-monetary Costs of travel

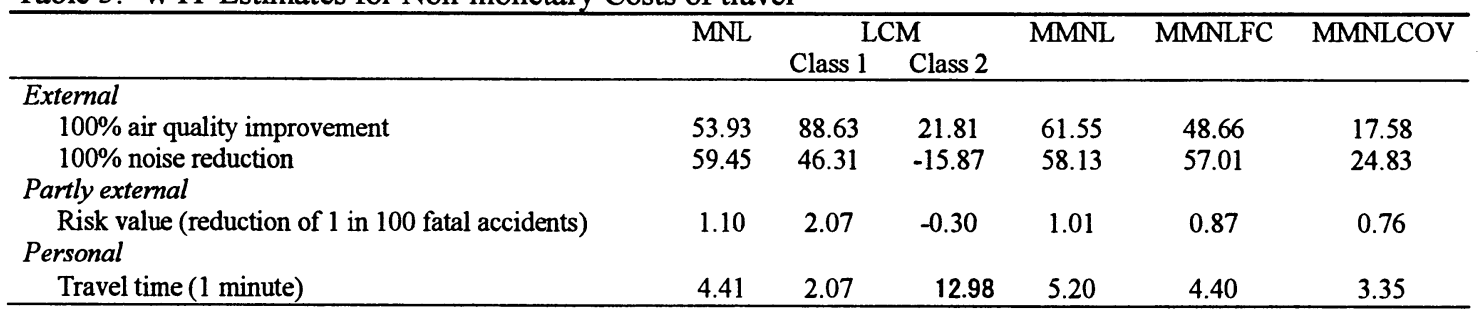

Figure 2 shows the cumulative distribution function (CDF) of the WTP from MMNLFC model. As expected in random parameter model, negative values are observed in all WTP estimates. Negative values are prominent in valuation of air and noise pollution which register $37 \%$ and $36 \%$ negative values respectively. On the other hand, time and fatal accident WTP likewise have $16 \%$ and $23 \%$ negative values. As expected, respondents have more certain preferences for variables of direct implications than that of the external variables.

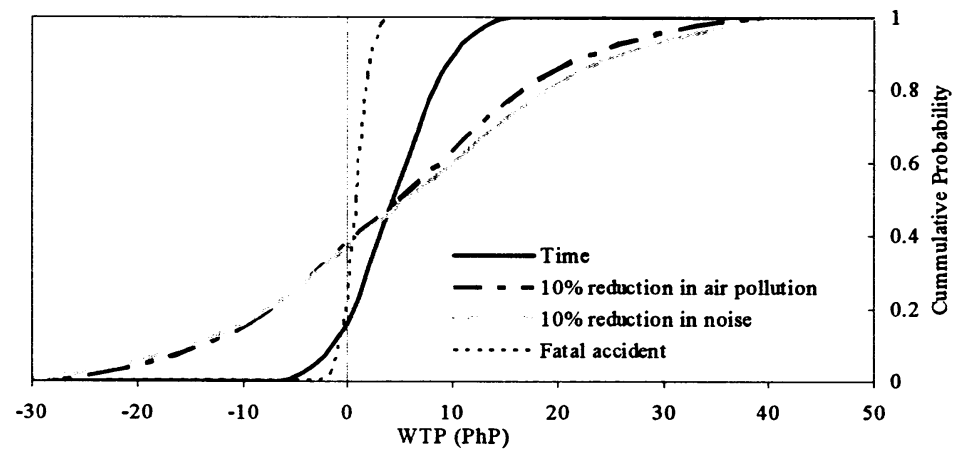

Figure 2: WTP distribution from the MMNLFC

Using value estimates from MMNLCOV model, the value must be first adjusted according to the actual income structure of Metro Manila's population. The income adjusted value for mean WTP are $3.27 \mathrm{PhP}$ for 100 percent air improvement, $4.61 \mathrm{PhP}$ for $100 \%$ improvement in noise, $0.14 \mathrm{PhP}$ to avoid risk of $1 \mathrm{in}$ 100 traffic fatalities in a year, and $0.62 \mathrm{PhP}$ value of travel time savings per minute.

The estimates here can be used to compute non-monetary external costs of various policy options in controlling air and noise pollution, and improving road safety in Metro Manila. In air pollution control for instance, these values complements the values estimated from other reports ${ }^{16) 18)}$ estimated through market-based and command-and-control measures. It can also provide clear monetary benefits estimate of environmental targets such as bringing the down the 2001 level of TSP to the national standard level means a non-use benefits of about $80 \mathrm{M} \mathrm{PhP} \mathrm{(1.5} \mathrm{M} \mathrm{US \$ )} \mathrm{in} \mathrm{the} \mathrm{transport} \mathrm{sector} \mathrm{a} \mathrm{day.}$

\section{Conclusion and recommendation}

This paper contributes to the limited number of literature on non-monetary social costs valuation of motor-vehicle use particularly in developing countries. We presented here an empirical application on the valuation of non-monetary costs of transport through stated preference internet survey. 
We show that in non-monetary valuation, latent heterogeneity significantly affect WTP estimates particularly those of non-personal, non-use, or indirect nature like the air quality and noise. Results of data estimations show that both LCM and MMNL provide more robust estimate than fixed MNL model. In terms of multi-attribute analysis of environmental change, better interpretation of the model can be done using MMNL on the context of variation of attribute parameter across individuals, and inherent correlation structure depicting how respondents perceive multi-attribute choices. LCM may be limited as its assumption in the parameterization of model is quite limited compared to MMNL. Nonetheless, LCM can more or less provide an indication of the difference of parameter across segment. In terms of estimation, however, given good data, LCM uses much lesser computer time than the MMNL model.

In multi-attribute analysis of environmental change, better interpretation of the model can be done using random taste coefficient models on the context of variation of attribute parameter across individuals, and inherent covariance structure depicting how respondents perceive multi-attribute choices. Random coefficient models are therefore better estimated in project evaluation involving multi-attribute environmental change. Based on LCM model, for instance, it can be seen that population is possibly segmented according to the environment-oriented segments and the time-oriented, risky segments. WTP significantly differ according to these segments. In MMNL logit models, it should also be understood that reliability of estimates of random parameter models depends on the specification of the models. In terms of the parameter of the cost vector, estimates can be tighter if cost parameter is held fix. On the correlation structure of the environmental attributes vectors, including covariance in the attributes improve both model and estimates. Based on the estimations done in this study, the authors recommend use of mixed logit with covariance for the attribute set to better explain goods in question.

\section{Acknowledgement}

We would like to express our gratitude to three anonymous reviewers whose invaluable comments helped improve the quality of this paper. Any remaining errors are sole responsibility of authors.

\section{References}

1) Mobility 2030: meeting the challenges to sustainability. World Business Council for Sustainable Development, Conches-Geneva, Switzerland, 2004.

2) Murphy, J. and M. A. Delucchi: Review of some of the literature on the social cost of motor-vehicle use. Institute of Transportation Studies University of California, Davis, Calif., 1996.

3) Murphy, J., M. A. Delucchi and University of California Davis. Institute of Transportation Studies.: Review of some of the literature on the social cost of motor-vehicle use. Institute of Transportation Studies University of California, Davis, Calif., 1996.

4) Greene, D. L., D. W. Jones and M. A. Delucchi: The full costs and benefits of transportation : contributions to theory, method, and management. Springer Verlag, Berlin ; New York, 1997.

5) Rennings, K., O. Hohmeyer and R. L. Ottinger: Social costs and sustainable mobility : strategies and experiences in Europe and the United States. Physica-Verlag Heidelberg, New York, and Mannheim, 2000.

6) MacKenzie, J. J., R. C. Dower, D. D. T. Chen and World Resources Institute.: The going rate : what it really costs to drive. World Resources Institute, Washington, D.C, 1992.

7) Delucchi, M. A. and University of California Davis. Institute of Transportation Studies.: The annualized social cost of motor-vehicle use in the U.S., 1990-1991: summary of theory, data, methods and results. Institute of Transportation Studies University of California, Davis, Calif., 1998.

8) Ketcham, B. and C. Komanoff: Win-win transportation: A no-losers approach to financing transport in New York City and the region, draft, Transportation Alternatives, 1992.

9) Turner, R. K., J. Paavola, P. Cooper, S. Farber, V. Jessamy and S. Georgiou: Valuing nature: lessons learned and future research directions. Ecological Economics, Vol. 46, No. 3, pp. 493-510, 2003.

10) Greene, W. H. and D. A. Hensher: A latent class model for discrete choice analysis: contrasts with mixed logit. Transportation Research Part B: Methodological, Vol. 37, No. 8, pp. 681-698, 2003.

11) Arana, J. E. and C. J. Leon: Flexible mixture distribution modelling of dichotomous choice contingent valuation with heterogeneity. Journal of Environmental Economics and Management, Vol. 50, No. 1, pp. 170-188, 2005.

12) Milon, J. W. and D. Scrogin: Latent preferences and valuation of wetland ecosystem restoration. 
Ecological Economics, In Press, Corrected Proof.

13) Kaiser, F. G., S. Wolfing and U. Fuhrer: Environmental attitude and ecological behavior. Journal of Environmental Psychology, Vol. 19, No. 1, pp. 1-19, 1999.

14) Metro Manila Urban Transportation Integration Study. JICA, 1998.

15) Roth, G. and J. O. Villoria: Finances of Commercialized Urban Road Network Subject to Congestion Pricing. Transportation Research Record, No. 1747, 2004.

16) Larssen, S., F. Gram, L. O. Hagen, H. Jansen, X. Olsthoorn, R. Lesaca, et al.: Urban Air Quality Management Strategy in Asia (URBAIR). 26302, J. Shah and T. Nagpal eds. International Bank of Reconstruction and Development/ The World Bank, Washington D.C., 1996.

17) Fabian, H. G. and K. N. Vergel: Analysis of Air Pollution Exposure of Individuals in the Road Environment. Journal of the Eastern Asia Society for Transportation Studies, Vol. 4, No. 5, pp. 55-70, 2001.

18) Krupnick, A., R. Morgenstern, C. Fisher, K. Rolfe, J. Logarta and B. Rufo: Air Pollution Control Policy Options for Metro Manila. Resources for the Future, Washington D.C., 2003.

19) De Leon, M. R., P. C. Cal and R. G. Sigua: Estimation of Socio-Economic Cost of Road Accidents in Metro Manila. Journal of the Eastern Asia Society for Transportation Studies, Vol. 6, pp. 3183 - 3198, 2005.

20) Adamowicz, W., J. Louviere and J. Swait: Introduction to Attribute-Based Stated Choice Methods. NOAA, 1998.

21) McFadden, D.: Rationality for Economist. Journal of Risk and Uncertainty, Vol. 19, No. 1-3, pp. 73-105, 1999.

22) Wardman, M. and A. L. Bristow: Traffic related noise and air quality valuations: evidence from stated preference residential choice model. Transportation Research Part D, Vol. 9, pp. 1-27, 2004.

23) Heiner, R. A.: The origin of predictable behavior. American Economic Review, No. 73, pp. 560-595, 1983.

24) Swait, J. and W. Adamowicz: Choice Environment, Market Complexity, and Consumer Behavior: A Theoretical and Empirical Approach for Incorporating Decision Complexity into Models of Consumer Choice. Organizational Behavior and Human Decision Processes, Vol. 86, No. 2, pp. 141-167, 2001.

25) Hess, S., M. Bierlaire and J. W. Polak: Estimation of value of travel-time savings using mixed logit models. Transportation Research Part A: Policy and Practice, Vol. 39, No. 2-3, pp. 221-236, 2005.

26) Provencher, B. and R. C. R. C. Bishop: Does accounting for preference heterogeneity improve the forecasting of a random utility model? A case study. Journal of Environmental Economics and Management, Vol. 48, No. 1, pp. 793-810, 2004.

27) Lee, B. J., A. Fujiwara, J. Zhang and Y. Sugie: Analysis of mode choice using latent class model 10th International Conference in Travel Behaviour Research. Lucerne, 2003.

28) Swait, J.: A structural equation model of latent segmentation and product choice for cross-sectional revealed preference choice data. Journal of Retailing and Consumer Services, Vol. 1, No. 2, pp. 77-89, 1994.

29) Bhat, C. R.: Endogenous segmentation mode choice model with an application to intercity travel. Transportation Science, Vol. 31, No. 1, pp. 34-48, 1997.

30) Greene, W. H.: Econometric Analysis, 5th ed. Prentice Hall, New Jersey, 2003.

31) Dempster, A. P., N. M. Laird and D. B. Rubin: Maximum Likelihood from Incomplete Data via EM algorithm. Journal of Royal Statistical Society, Vol. B, No. 39, 1977.

32) Roeder, K., K. G. Lynch and D. S. Nagin: Modeling Uncertainty in Latent Class Membership: A Case Study in Criminology. Journal of the American Statistical Association, Vol. 447, pp. 766-776, 1999.

33) Train, K.: Discrete choice methods with simulation. Cambridge University Press, New York, 2003.

34) Bierlaire, M.: BIOGEME: a free package for the estimation of discrete choice models Proceedings of the 3rd Swiss Transport Research Conference. Monte Verita, Ascona, Switzerland, 2003.

35) Walker, J. and M. Ben-Akiva: Generalized random utility model. Mathematical Social Sciences, Vol. 43, No. 3, pp. 303-343, 2002.

36) Brownstone, D. and K. Train: Forecasting New Product Penetration with Flexible Substitution Patterns. Journal of Econometrics, Vol. 89, No. 1-2, pp. 109-129, 1999. 


\title{
Latent heterogeneity in WTP estimates of non-market costs of motor-vehicle use using multi-attribute stated choices*
}

$$
\text { by Michelle PARUMOG**, Shoshi MIZOKAMI***, and Ryuji KAKIMOTO**** }
$$

Stated choice experiments eliciting willingness to pay (WTP) for environmental goods and services provide means to assign monetary estimates to the social and environmental costs of motor-vehicle use such as air pollution, noise and congestion. However, recent findings that stated choices are affected by unobserved variables such as attitudes, perceptions, and preferences prompted the need to develop models that consider latent heterogeneity in WTP estimates. This paper investigates latent heterogeneity in preferences for environmental goods as affected by attribute tastes differences in an internet-based survey on the valuation of road and roadside environment in Metro Manila. We compare two models considering random taste parameter, namely, latent class model and mixed multinomial logit. The implications of the models and WTP estimates in practice and policy-making are likewise discussed.

\section{多属性選好意向調査を用いた自動車利用の社会的費用の推定における潜在的選好異質性}

\author{
Michelle PARUMOG**, 溝上章志***, 柿本竜治****
}

環境などの非市場財に対する支払い意志額を聞く選択意向調査では, その推定に態度や知覚, 選好 などの非観測変数が影響を与えるために, 潜在的選好異質性を考慮した支払い意志額推定モテルを開 発することが求められている. 本研究では, マニラ都市圈における利用経路と沿道環境の価值評価に 関するウェブ調査によって，環境財に対する選好における潜在的選好異質性を，潜在クラスモデルと Mixed Logit モデルによって分析した. その結果, これらの方法は支払い意志額の推定, および環境政 策の立案に有用であることが明らかになった. 